Journal of English Language Teaching and Applied Linguistics

ISSN: 2707-756X

DOI: $10.32996 /$ jeltal

Journal Homepage: www.al-kindipublisher.com/index.php/jeltal

JELTAL

\title{
Rhetorical Analysis of the Use of Metaphor in Ghana's First and Former President, Dr. Kwame Nkrumah's Political Speeches
}

\author{
Sandra Addo Wiredu 8 (D) \\ MA in Foreign language and Literature. Department of Linguistics. Nanjing Tech University, Nanjing, China \\ 凶Corresponding Author: Sandra Addo Wiredu, E-mail: Sandrawiredu1@gmail.com
}

ARTICLE INFORMATION ABSTRACT

Received: August 13, 2021

Accepted: September 15, 2021

Volume: 3

Issue: 10

DOI: $10.32996 /$ jeltal.2021.3.10.2

\section{KEYWORDS}

Metaphor, colonialism, rhetoric, demonize
In the late 1970s, linguists such as George Lakoff, Mark Johnson, and Michael Reddy began to realize that metaphor was extremely common and related to thought and action. Indeed, they claimed that "our conceptual system...is fundamentally metaphoric in nature" (Lakoff and Johnson, 1980). Owing to this, metaphor is used in all-out endeavours: socially, economically, politically, etc. From this perspective, this paper analyzes the use of metaphor in a corpus of speeches delivered by a prominent figure in Ghanaian politics. This is none other than one of the pioneers of African emancipation, the former and first president of the Republic of Ghana Dr. Kwame Nkrumah, in his fight for Independence for Ghana and African unity. It portrays the use of metaphor as a powerful tool to convey information, thereby making it more convincing to serve its intended purpose. It also reveals how Dr. Kwame Nkrumah (Ghana's first president) used rhetoric to achieve his political aims. It unravels the metaphors used in his speech delivered on 10th July 1953, which is collected from samples of his speeches published online. Secondly, this paper adopts the use of MIPVU (which is a systematic and transparent procedure for identifying linguistic metaphors). It achieves inter-coder reliability and does not identify conceptual metaphors. By adopting MIPVU, lexical units of the sentences will be examined and then the contextual meaning of the unit will be established to determine more basic meaning. If the contextual meaning contrasts with the basic meaning but can be understood in comparison with it, then the unit will be marked as a metaphor. When the metaphor was identified, I used critical discourse analysis (CDA) methodology for data analysis. This paper's findings clearly demonstrate that the metaphor is predominant in political discourse and can actually trigger social action.

\section{Introduction}

Language is vital to the process of transforming political will into social action, 'in fact, any political action is prepared, accompanied, controlled and influenced by language' (Schäffner 1997: 1). The more democratic societies become, the greater the leaders of the power have to convince potential followers that they and their policies can be heard. In the recent past, the political field has placed much attention on certain languages, which came to prominence for various military, economic and cultural reasons. It is important to know that the more powerful languages become, the more they are prone to create agreements as well as trigger an uproar when people find the need to. The degree to which languages of power overshadow and eventually suppress other languages is quite alarming. This comes with its own benefits. A rightful command of the language of a person's region and beyond can be an important factor for gaining access to influential positions in society. However, those people such as political leaders who gain such power sometimes use it to persuade a large number of people to usher them into social action and this is what Dr. Kwame Nkrumah used to achieve his political goals.

Dr. Kwame Nkrumah (1909-1972) was a Ghanaian politician and revolutionary. He was the first prime minister and president of Ghana, having led the Gold Coast to Independence from Britain in 1957. He was considered one of the best leaders in Africa and

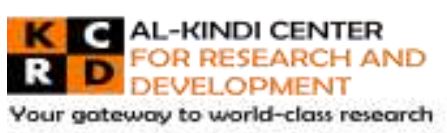

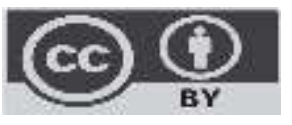

Published by Al-Kindi Center for Research and Development, United Kingdom. Copyright (c) the author(s). This open access article is distributed under a Creative Commons Attribution (CC-BY) 4.0 license 
he was one of the main catalysts of the African independence revolution in the 1950s and 1960s and his political rhetoric influenced world affairs in the $20^{\text {th }}$ Century. According to research, a strategic weapon that contributed to his powerful rhetoric was his use of metaphor. This thesis seeks to dive into the use of metaphors in Kwame Nkrumah's discourse on colonialism and emancipation and how he used the power in rhetoric to achieve his long term and short-term political goals.

\subsection{Objective of the study}

This study aims to identify the metaphors in Dr. Kwame Nkrumah's political speeches and rhetorically analyze the data collected. The main focus will specifically be on the one delivered before the independence of Ghana on $10^{\text {th }}$ July 1953 , House of Commons, UK.

\subsection{Research questions}

The following questions will be addressed.

- Is the use of metaphor predominant in Dr. Kwame Nkrumah's political speeches?

- What are the implications of the use of metaphor in Dr. Kwame Nkrumah's political speeches?

\section{Literature Review}

\subsection{Metaphor}

Metaphor is a rhetorical figure that compares two things that are from "different classes of experience", which in turn creates a new understanding through the specific use of language (Burkholder \& Henry 2009: 98). It may be worth pointing out that the classical notion of metaphor is very different from modern views associated with the concept. Aristotle (1991) sees the metaphor in two main discursive locations: the place where it originated from and the place to which it has been transferred. According to Aristotle, the two main parts of the metaphor work on each other by sharing some obvious features, Black (1962) offers a different view on the metaphor. He refers to Aristotle's theory as a comparison theory in which there are pre-existing similarities between the two things being compared. According to Black, when we say "man is a wolf" we do not simply rub onto man the pre-existing characteristics of a wolf but rather: get man newly involved in a system of commonplace or an "implicative complex" about wolf. For Black, this metaphor: "man is a wolf" changes our notion about both man and wolf. This is a major departure from the classical notion of the metaphor.

In terms of function, metaphor allows the reader a greater understanding of the concept, object, or character being described. This is the first and most practical function of metaphors. Additionally, metaphor can be used for embellishment purposes, as it can create an image that is beautiful or profound or otherwise produces the effect that the writer desires. For these reasons, metaphor has been extensively used in the West since Homer's lliad (e.g., Zanker 2019). For instance, metaphors have been used to talk or write about a variety of issues, such as economics (Morris, Sheldon, Ames, \& Young 2007), health (Nerlich, Hamilton, \& Row 2002), and politics (e.g., Mio 1997; Charteris-Black 2006; Musolff 2016). In politics, metaphors act as a rhetorical device aimed at characterizing political figures, opponents, events and citizens in persuading them towards a specific point of view. In most cases, politicians' main goal is not primarily to present factual arguments but rather to be persuasive. Consequently, the speaker needs to use skilful language to appeal to people's emotions and include and affect the audience.

Over the past two decades, scholars from different research backgrounds have extensively studied the effects of metaphorical framing on political persuasion (e.g., Mio 1997; Charteris-Black 2006; Musolff 2010, 2012, 2016). This thesis seeks to examine the use of metaphors in Dr. Kwame Nkrumah's political speeches and their rhetorical effects on Ghanaians and beyond.

\subsection{Critical discourse analysis}

As a direct consequence of the use of discourse analysis to linguistic inquiry, several studies within linguistics, especially applied linguistics, have for some time now focused on discourse analytical research in the various discourse of textual domains. This has resulted in a flurry of research on both oral and written texts in areas such as education (Warren, 2011a; King, 2016; Li, 2016; Lu, Li \&Ottewell, 2016), business (Cheng \& Warren, 2005; Warren, 2007; 2011b), law (Warren \& Leung, 2013; Hutton, 2014; Cheng, Cheng \& Li, 2015), medicine (Yanoff, 1988; Waitzkin, 1989), politics (Habwe, 1999; Post, 2009; Li, Cheng \& Cheng, 2016), workplace (Holmes, 2006; 2007; 2015; Marra, King \& Holmes, 2014), media (Cheng \& Lam, 2010), among others. These studies have investigated a number of linguistic features, including cohesion and coherence (Halliday \& Hasan, 1976), metadiscourse (Hyland, 2004), conversational strategies (Wooffitt, 2005; Heritage, 2005), quotative markers (King, 2010) and implicatures (Yule, 2010). These studies have shed light on the communicative purpose of language and highlighted the power of language in operation, but have also contributed immensely to the development of valuable pedagogical and instructional materials for English for Specific Purposes (ESP).

Critical discourse analysis (CDA) emerged in the early 1990s to explore the relationship between language, ideology, and power. CDA emerged from critical linguistics and critical semiotics and is, generally, "a socio-politically conscious and oppositional way 
of investigating language, discourse and communication" (van Dijk, 1995a, p. 17). In CDA, thus, the concern is not to analyze or describe language and text for its own sake but to look at how context triggers social action. "CDA deals with the discursively enacted or legitimated structures and strategies of dominance and resistance in social relationships" (van Dijk, 1995a, p. 18). In sum, CDA adopts a critical focus in studying the functions of discourse in society, noting the expression, representation, legitimation or reproduction of societal ways, including forms of inequality, in text and talk.

Since its inception in 1990, CDA has been used to analyze text and/or discourse in various domains of language use. For example, it has been utilized to examine academic discourse (e.g., Zotsmann, 2006; Mohammed, 2006), media discourse (e.g., Wodak\& Busch, 2004; Richardson, 2007; Ramanathan \&Hoon, 2015), familial/domestic discourse (e.g., Rogers, 2002; Smythe, 2006), colonial discourse (e.g., Sabido, 2013; 2015), legal discourse (e.g., Enein, 1999; Hutton, 2009; Edu-Buandoh\&Ahialey, 2012) and religious discourse (e.g., Eldin, 2014; Hjelm, 2014). It has also been used to investigate discourse on advertising (e.g., Vahid, 2012; Tahmasbi, 2013; Iqbal, Danish \& Tahir, 2014), discourse on terrorism and warfare (Bhatia, 2009; Sarfo \&Krampa, 2013), feminist discourse (e.g., Lazar, 2005; McLoughlin, 2017) and political discourse (e.g., Flowerdew, 1997a; 1997b). These studies have revealed that institutional discourse both shapes and is shaped by various competing ideologies and power relations. As well, they have demonstrated the often non-neutral and taken-for-grantedness of language use (and abuse).

In the last decade, the discourse of prominent politicians, especially presidential rhetoric, has also gained attention in CDA research. In his monograph on politics and metaphor, for instance, Charteris-Black (2011) examined the rhetoric of as many as nine politicians, including Winston Churchill, Martin Luther King, Enoch Powell, Ronald Reagan, Margaret Thatcher, Bill Clinton, Tony Blair, George Bush and Barack Obama. Studies on United States presidential rhetoric have also been prevalent (see Campbell \& Jamieson, 1990; Snyder \& Higgins, 1990; Lim, 2002). While some of these studies employed CDA as the sole approach/framework (e.g., Aschale, 2013; Bartolucci, 2010), others have integrated CDA with other frameworks such as critical literacy pedagogy (Abida\&Shakila, 2015), contrastive analysis (Schroter \& Storjohann, 2015), conversation analysis (e.g., Korobov, 2001), genre theory.

\subsection{MIPVU}

it was not until 2007 before a procedure for metaphor identification was established. It was done by a group of researchers which called themselves Pragglejaz group. Their method called MIP (Metaphor Identification Procedure; Pragglejaz group (2007)) was then refined in several ways and applied to data from The British National Corpus. The upgraded procedure is called MIPVU and the resulting annotated source is VU Amsterdam Metaphor Corpus (VUAMC; Steen et al., 2010). It consists of approximately 200,000 words taken from the BNC's Baby Corpus and it is divided into four genres: academic, news, fiction, and conversation. In MIPVU, lexical units (words) with contextual meanings instead of their basic meanings are considered metaphor-related words (MRWs). Annotators establish the basic and the contextual meaning for each word in the corpus using a dictionary. If the basic meaning of a word is: a) more concrete; what it evokes is easier to imagine, see, hear, feel, smell and taste; b) related to bodily action; c) more precise (as opposed to vague); the word is marked as MRW. The history of a lexical unit is usually not taken into account, which is one of the differences between MIP and MIPVU.

\section{Data and methodology}

The data is a corpus of materials or data found on previous articles/ speeches published online. This comprises of the political speeches delivered by Dr. Kwame Nkrumah on colonialism and emancipation. Also, the linguistic metaphor identification procedure (MIPVU), proposed by Gerard Steen (2010), will be adopted to identify the metaphors used in the corpus. A theoretical framework integrating Cognitive Linguistics and Critical Discourse Analysis (CDA) will be used to analyze the metaphors identified.

\subsection{Significance of the study.}

This paper will contribute to Ghana/Africa's political history by enhancing our existing understanding of Nkrumah's rhetorical use of language. It will also add to previous findings and various perspectives on Nkrumah's socio-political thought and the effects of his persuasive language throughout his political life. 


\section{Selected Speeches}

\section{Findings and Discussions}

The following extracts used in this paper is a speech delivered by Dr. Kwame Nkrumah on "The Motion of Destiny" at the House of Commons in England, 1953.

".... Mr. Speaker, we have frequent examples to show that there comes a time in the history of all colonial peoples when they must, because of their will to throw off the hampering shackles of colonialism, boldly assert their God-given right to be free of a foreign ruler. Today we are here to claim this right to our independence..."

The above extract is a typical instance where Nkrumah used metaphor to convey his message. He uses "a shackle" to portray how colonialism really is and how they "the colonized" feel in their own motherland. Considering the fact that Ghana (then Gold Coast) is their own motherland, from where they were born and bred, was taken over by foreign rule, who brought their own culture and peculiar way of doing things to their country, and thereby throwing away their own culture and subsequently their identity. Nevertheless, their culture was over ruled by foreign norms, so they felt lost or otherwise enslaved. What is a shackle? A shackle is a pair of iron rings joined by a chain put on a prisoner's wrists, ankles etc. to limit movement. From this viewpoint, Nkrumah postulates that Colonialism is nonetheless an entangling shackle, which on the contrary to the norm (placed on gates for protection or the like) is locked around the legs and hands of the people of Ghana, this time not for protection but as a barrier to their God given rights. Therefore, the people of Ghana are nonetheless "prisoners". This clearly shows that Nkrumah sees colonialism as a whole prison on its own. Again, he describes "shackles" with hampering', which is to moderate or limit the effect of full exercise. This means that colonialism is so entangling to the extent that, aside from being chained, the people are not able to do anything on their own, but rather, the new foreign rule with their culture, norms, values, political systems, economic system and even their food are being imposed on them. Therefore, they cannot fully experience their own culture and, more particularly, their God-given rights, hence the need to opt for freedom and abort colonialism forever.

\subsection{Nkrumah continues..........}

".... The right of a people to decide their own destiny, to make their way in freedom, is not to be measured by the yardstick of color or degree of social development. It is an inalienable right of peoples which they are powerless to exercise when forces, stronger than they themselves, by whatever means, for whatever reasons, take this right away from them."

Since by conduct, the British had postulated that the "Blackman" is incapable of managing its own affairs, Nkrumah emphasizes that, regardless of 'color" and social development, the people of Ghana (then Gold Coast) can manage their own affairs in a way that is more suitable to them. A yardstick is simply a small measuring tool that definitely, cannot be used to measure the possibility of some group of people managing their own affairs, not to talk of being imprisoned. Also, yardstick here can also mean "a standard of making a critical judgement" Nkrumah claims that the decision as to if a group of people can manage their own affairs is a critical judgement which definitely cannot be dependent on social development and particularly "color" of that particular group of people.

He mentions that the degree of social development does not make a difference at all and that, by the time the British arrived in Gold Coast, they had their own political, economic and social systems which were working in an optical way to pave the way for development. He proclaims that colonialism and all things associated with it are forces stronger than they themselves, imposing certain things on them. Using forces portrays that colonialism comes with some strange vibes that the local people cannot control nor overcome. To support this point of economic worthiness mentioned earlier, lets harness on his statement he made below;

"...t is said that lawyers and scholars were much respected in that empire and that the inhabitants of Ghana wore garments of wool, cotton, silk and velvet.

Nkrumah here is not only referring to the type of costumes in ancient Ghana per se. He was rather referring to the fact that they were rich and prosperous and that, they could manage their own affairs. So, if the Ghanaians cannot meet certain standards, it probably does not mean they are incapable of self-independence. That notwithstanding, he continued by saying.

"There was trade in copper, gold and textile fabrics, and jewels and weapons of gold and silver were carried."

This clearly illustrated that they were rich in their own motherland. Trade here refers to the economic stature. He claims that they had economic power and trade was successful. If the British trade in gold, they also used to trade through the same means and therefore, they are capable of managing their own affairs devoid of foreign influence. He made mention of "and weapons of gold and silver were carried.". This statement implied the security they commanded. That, they had sophisticated weapons 
with which they could have defended themselves. Here Nkrumah is propagating Economic and security readiness to support his motion of Independence to the British.

\subsection{He continues by demonizing colonialism...}

".......as an inspiration to continue their grim fight against cruelties which we in this corner of Africa have never knowncruelties which are a disgrace to humanity, and to the civilization which the white man has set himself to teach us."

Again, Nkrumah refers to colonialism as 'cruelty'. Cruelty is a behaviour that causes physical and mental harm to another, whether intentionally or not. When the British first arrived in Ghana, they came to trade and to introduce formal education. They would buy things like salt, gold and cocoa and sell to the people of Africa things such as guns, gun-powder and clothing. Soon the trade took a wrong turn and the Europeans began the slave trade - trading in human beings. They bought slaves from many parts of Africa - especially western Africa and took them outside the continent of Africa to work. Then, in the long run, before the people realised, they had already taken over Ghana and became masters. They delimited the powers of chiefs which the people regarded as their leaders and invested their trust in them and changed their long-cherished norms and values.

Nkrumah was not against the British coming to teach or trade with us, but rather was against the fact that they took over all systems and that everything was under control, so he describes it as a "cruelty" which is a disgrace to mankind. Therefore, colonialism is so terrifying that it must not be tolerated at all. Grim means something very serious or gloomy; sunshine, puppies, and rainbows are not grim; zombies, reaper and mummies are grim. As serious as it sounds and as helpless as he sounded, colonialism is a terror by which the people feel lost and disgraced. Hence instead of feeling lost, then it is better to die in the pursuit of fighting against it than living to be colonized.

As a matter of fact, as uncontrollable as it seemed, Nkrumah again refers to colonialism as a force, that is so scary and which Africans and, for that matter, Ghanaians have never seen. Grim fight here means an unpleasant and serious fight that his forefathers perpetuated against colonialism, which he, 'Nkrumah' intends to follow suit at all cost.

\subsection{Nkrumah envisions...}

"Our aim is to make this country a worthy place for all its citizens, a country that will be a shining light throughout the whole continent of Africa, giving inspiration far beyond its frontiers."

Nkrumah uses "shining light" to portray freedom against colonialism; by acquiring self-independence, Ghana will set an example for the rest of the continent. As a consequence of decolonization, the light of Ghana which was nevertheless doomed or turned off, shall overcome all its obstacles and shine bright again. It implied that any country colonized losses its identity is in darkness, colonialism, therefore, steal the original identity of countries and subsequently covers or automatically turns off the shining light and beauty of countries. Colonialism changes the beauty of countries by changing the lifestyles and traditions peculiar to that country which makes it unique. Therefore, by attaining independence, darkness falls off and the light of that particular country shines automatically. On the other hand, shining light also means the beauty of nations' traditions, culture, norms, values, systems, etc.

Nkrumah's use of language is purposely for Ghanaian freedom and set an example for the rest of the countries in the continent and beyond to follow. Since light shines more in darkness, the act of colonialism can also bring out the best in them through learning, useful adaptations and careful negotiations.

4.4. "And while yet we are making our claim for self-government I want to emphasize, Mr. Speaker, that self-government is not an end in itself. It is a means to an end, to the building of the good life to the benefit of all, regardless of tribe, creed, color or station in life."

Nkrumah mentions that 'self-government is a means to an end'. He envisions that driving away the British isn't the end of it all, that they are prepared to build a good life in the whole of Ghana and to achieve this, they will abort tribalism because colonialism has taught them the lesson that equality must be upheld and discrimination aborted. This means that, by ending colonialism, they intend to improve their standards of living. This will create a strong bond between the populace from all tribes and create a stronger Ghana, ready for self-governance and anything associated with it.

\subsection{Nkrumah concludes....}

"The strands of history have brought our two countries together. We have provided much material benefit to the British people, and they in turn have taught us many good things. We want to continue to learn from them the best they can give us and we hope that they will find in us qualities worthy of emulation. In our daily lives, we may lack those material comforts regarded as essential by the standards of the modern world, because so much of our wealth is still locked up in our land; but we have the gifts 


\section{of laughter and joy, a love of music, a lack of malice, an absence of the desire for vengeance for our wrongs, all things of intrinsic worth in a world sick of injustice, revenge, fear and want."}

The general view of Nkrumah describing colonialism with "grim" is that of violence. However, from the above extract, Nkrumah wants to propagate peace between the two countries and end colonialism without terror, as he seemed to have claimed from the above points he raised. As mentioned above, even when he describes colonialism as darkness, it brings out the shining light in them even more: colonialism will one day turn around for their good. First of all, the two countries met on an uncalled-for circumstance, yet Ghanaians, after some time, succumbed to them and, instead of rebelling against them, provided them with many things regardless of their unhappiness and uncertainty. The British, in turn, taught them many things which Nkrumah considered 'good'. Aside from the possibility of colonialism leaving them unpleasant memories and probably leaving them with an indelible mark, they will be happy to adopt all the good things colonialism brought even after independence and continue to fight the good fight of managing their own affairs.

In his last statement, he demonstrates what the British lack and what they have. That the British are hungry for power, so they rebel against countries. Their hearts are full of vengeance even when they are economically wealthy. Therefore, they lack internal and external peace because as they rebel, others also rebel against them and by so doing, it is perceived that their peace is destructed. On the contrary, taking a good look at the then Gold Coast, they were not fighting for external power at all. They were just minding their own business and living a happy life, to the extent of receiving foreigners with warmth and no malice. This is what Nkrumah suggests the British find in us, to learn to be peaceful and experience real happiness devoid of malice and the urge to rebel.

\section{Conclusion}

Political language is the language used as a political tool, such as languages of slogans or propaganda, government official languages in speech or language used in the speeches of party leaders and the writings about political themes that contain the intentions to achieve certain goals. (Darma, 2009, p. 91). This is what Kwame Nkrumah used to achieve his political aims

Nkrumah was a visionary leader who used rhetoric as a powerful weapon to achieve his political objectives and that is the sole aim of this paper: to rhetorically analyze or highlight the implications of his political speeches which he conveyed before the attainment of Ghana's independence. The extracts above show Nkrumah's use of expressions such as hampering shackles, forces, cruelty to describe colonialism, shows how he predominantly used rhetoric in metaphors to convince the house of commons to support the notion of independence.

In the findings and data collection section, Nkrumah, by demonizing colonialism with grim, is perceived that there would have been war and subsequently deaths, or probably serious injuries and properties destroyed. However, he perpetuates a peaceful end to colonialism by stating: "We want to continue to learn from them the best they can give us and we hope that they will find in us qualities worthy of emulation" This means that though the two countries met on the uncalled-for circumstance, Ghanaians have provided many things and the British have in return thought them many things they deem good. However, the bad things, particularly, colonialism must be aborted. By ending colonialism, the good things colonialism brought will be maintained or, nevertheless, improved upon.

This has been the case ever since the British were driven out. The first and most important practice which was adopted is Christianity. The majority of Ghanaians are Christians today and the good deeds in the Bible are socially accepted deeds, whereas society frowns upon the bad deeds in the Bible. Moreover, the introduction to the English language has done better than harm to the populace. It is our official language and has contributed to a more modern Ghana. It is also the language of instruction in all institutions. On the other hand, the educational, political and economic systems were maintained with minor or no amendments.

There were few limitations to this study; the most prominent was the difficulty of finding the recorded version or audio on YouTube. The various audios found was a compilation of some extracts from Dr. Kwame Nkrumah's different political speeches. As a result, the data used in this paper heavily relied on published papers online. That notwithstanding, the data collected from Speakola tallied with other papers published elsewhere.

In a nutshell, I agree with Nkrumah for demonizing colonialism and perpetuating a ruthless war against it. Something that deprives others of their God-given rights is indeed cruelty beyond measure and a total disgrace to those who practice it and its victims as well. If the next world exists, I hope that 'colonialism' will not be in our dictionaries. Shalom. 
Funding: The author of this work solely funded it.

Conflicts of Interest: The author declares no conflict of interest.

\section{References}

[1]. Kövesces, Z. (2002). Metaphor: A practical introduction (2nd ed.). New York: Oxford University Press.

[2]. Lakoff, G. \& Johnson, M. (1980). Metaphors we live by. Chicago/London: University of Chicago Press.

[3]. Mensah, E. O. (2014). The rhetoric of Kwame Nkrumah: Analysis of his political speeches (Doctoral dissertation). University of Cape Town, Cape Town.

[4]. Mensah, E. O. (2019). The constraint of a rhetorical invention: Kwame Nkrumah and the organization of African unity. Lagos notes and records, 25(1), 62-88.

[5]. Mio, J. S. (1997). Metaphor and politics. Metaphor and Symbol, 12(2), 113-133.

[6]. Monfils, B. S. (1977). A multifaceted image: Kwame Nkrumah's extrinsic rhetorical strategies. Journal of Black Studies, 7(3), $313-330$.

[7]. Musolff, A. (2010). Political metaphor and bodies politic. In U. Okulska \& P. Cap (Eds.), Perspectives in politics and discourse (pp. 23-41). Amsterdam: John Benjamins.

[8]. Musolff, A. (2012). The study of metaphor as part of critical discourse analysis. Critical Discourse Studies, 9(3), 301-310.

[9]. Musolff, A. (2016). Political metaphor analysis: Discourse and scenarios. London/ New York: Bloomsbury Academic.

[10]. Nartey, M. (2019a). 'I shall prosecute a ruthless war on these monsters...': A critical metaphor analysis of discourse of resistance in the rhetoric of Kwame Nkrumah. Critical Discourse Studies, 16(2), 113-130.

[11]. Nartey, M. (2019b). "We must unite now or perish!": Kwame Nkrumah's creation of a mythic discourse? Journal of Language and Politics, 18(2), 252-271.

[12]. Nartey, M. (2020a). Metaphor and Kwame Nkrumah's construction of the unite or perish myth: A discourse-mythological analysis. Social Semiotics, 30(5), 646-664.

[13]. Nartey, M. (2020b). A critical metaphor analysis of heroic myth in the discourse of Kwame Nkrumah. Critical Approaches to Discourse Analysis across Disciplines, 12(1).

[14]. Obeng, S. (Ed.) (1997). Selected Speeches of Kwame Nkrumah (5 volumes). Accra: Afram Publications.

[15]. Partington, A., \& Taylor, C. (2018). The language of persuasion in politics: An introduction. New York: Routledge.

[16]. Perrez, J., Reuchamps, M., \& Thibodeau, P. H. (Eds.). (2019). Variation in political metaphor. Amsterdam: John Benjamins.

[17]. Pettiway, K. M. (2016). A new African in the world: A rhetorical study of Kwame Nkrumah's visual strategy for shaping postcolonial nationhood. (Doctoral dissertation). North Carolina State University, Raleigh.

[18]. Semino, E., \& Demjén, Z. (2016). The Routledge Handbook of Metaphor and Language. New York: Routledge.

[19]. Wodak, R., \& Forchtner, B. (Eds.). (2017). The Routledge handbook of language and politics. New York: Routledge.

[20]. Kwame Nkrumah: 'Today we are here to claim this right to our independence', Motion of Destiny - 1953 - Speakola. 